\title{
Early changes in the haemostatic and procoagulant systems after chemotherapy for breast cancer
}

\author{
CC Kirwan', G McDowell, ${ }^{2,3}$ CN McCollum', S Kumar ${ }^{4}$ and GJ Byrne ${ }^{*, 1}$ \\ 'Department of Surgery, South Manchester University Hospitals Trust, Wythenshawe Hospital, Southmoor Road, Manchester M23 9LT, UK; \\ ${ }^{2}$ Department of Clinical Biochemistry, Manchester Royal Infirmary, Oxford Road, Manchester M I 3 9WL, UK; ${ }^{3}$ Department of Pathology, Manchester \\ Medical School, Oxford Road, Manchester MI 3 9PT, UK; ${ }^{4}$ Department of Pathology, University of Manchester and Christie Hospital NHS Trust, \\ Manchester Medical School, Oxford Road, Manchester MI 3 9PT, UK
}

Venous thromboembolism (VTE) following breast cancer chemotherapy is common. Chemotherapy-induced alterations in markers of haemostasis occur during chemotherapy. It is unclear how rapidly this occurs, whether this is upregulated in patients developing VTE and whether changes predict for VTE. Markers of haemostasis, functional clotting assays and vascular endothelial growth factor were measured before chemotherapy and at 24 h, 4 days, 8 days and 3 months following commencement of chemotherapy in early and advanced breast cancer patients and in age- and sex-matched controls. Duplex ultrasound imaging was performed after I month or if symptomatic. Of 123 patients, 9.8\% developed VTE within 3 months. Activated partial thromboplastin time (APTT), prothrombin time (PT), D-dimer, fibrinogen, platelet count, VEGF and fibrinogen were increased in cancer. Fibrinogen, D-dimer, VEGF and tissue factor were increased, at baseline, in patients subsequently developing VTE. D-dimer of less than $500 \mathrm{ng} \mathrm{ml}^{-1}$ has a negative predictive value of $97 \%$. Activated partial thromboplastin time, PT and thrombin-antithrombin showed significantly different trends, as early as within $24 \mathrm{~h}$, in response to chemotherapy in patients subsequently developing VTE. Markers of coagulation and procoagulants are increased, before chemotherapy, in patients who subsequently develop VTE. A group of patients at minimal risk of VTE can be identified, allowing targeted thrombopropylaxis to the higher risk group.

British Journal of Cancer (2008) 99, 1000- 1006. doi:I0.1038/sj.bjc.6604620 www.bjcancer.com

Published online 2 September 2008

(C) 2008 Cancer Research UK

Keywords: breast cancer; chemotherapy; venous thromboembolism; procoagulants

Venous thromboembolism (VTE) following breast cancer chemotherapy is not uncommon. In early breast cancer, VTE occurs in $5-10 \%$ of patients receiving chemotherapy (Weiss et al, 1981; Levine et al, 1988; von Tempelhoff et al, 1996), with a mortality of $0.2-0.5 \%$ (Weiss et al, 1981; Clahsen et al, 1994). Venous thromboembolism rises to approximately $18 \%$ in advanced breast cancer (Goodnough et al, 1984), with a mortality of $9 \%$. Approximately two-thirds of all VTEs occur within 3 months of commencing chemotherapy (von Tempelhoff et al, 1996; Seward et al 1999); however, despite this, thromboprophylaxis is rarely used (Kirwan et al, 2003).

Previous work has demonstrated a hypercoagulable state in breast cancer patients, with elevated markers of coagulation, including thrombin-antithrombin (TAT) (Falanga et al, 1998; Ozyilkan et al, 1998), fibrinogen (Miller and Heilmann, 1988), D-dimer (Blackwell et al, 2000; Oberhoff et al, 2000) and tissue factor (TF) (Lwaleed et al, 1999; Ueno et al, 2000).

Several small studies have reported alterations in markers of coagulation in response to breast cancer chemotherapy, which support the development of a chemotherapy-induced hypercoagulable state (Canobbio et al, 1986; Rogers et al, 1988; Feffer

*Correspondence: Mr GJ Byrne; E-mail: gedbyrne@compuserve.com Received 17 April 2008; revised 17 July 2008; accepted 27 July 2008; published online 2 September 2008 et al, 1989; Rella et al, 1996; Pectasides et al, 1999). Several pathogenic mechanisms have been suggested such as increased expression or release of procoagulants and cytokines from damaged cells, a direct toxic effect on vascular endothelium or upregulation of platelet or monocyte activity. Although it is widely accepted that development of VTE is multifactorial, the increased rate of chemotherapy-induced VTE occurring in advanced breast cancer patients as compared with adjuvant patients suggests that other mechanisms may be occurring in the former group. It has been postulated that the direct toxic effect of chemotherapy on cancer cells may lead to increase in circulating tumour cell fragments or microparticles with associated procoagulant activity (Dvorak et al, 1983).

To date, the speed of onset of biochemical alterations in haemostasis remains to be elucidated. Moreover, no study has related cancer load to haemostatic and circulating procoagulant response to chemotherapy.

Preoperative D-dimer, prothrombin fragments 1 and $2(\mathrm{PF} 1+2)$ and TAT have been shown to have some value in predicting postoperative VTE in patients undergoing major orthopaedic surgery (Bongard et al, 1994; Ginsberg et al, 1995; Cofrancesco et al, 1997; Lowe et al, 1999); however, markers of hypercoagulability and D-dimer were found to be of no use in predicting VTE in acutely ill medical patients (Crowther et al, 2005). Preoperative $\mathrm{PF} 1+2$, TAT and soluble fibrin do not predict postoperative DVT in colorectal cancer patients; however, postoperative (days 1-7) 
levels predict DVT, before a clinical diagnosis has been made (Iversen and Thorlacius-Ussing, 2002).

Although several studies have investigated haemostatic responses to chemotherapy at a biochemical level, no study to date has related these to the development of VTE, with a view to identifying patients at increased risk of thrombosis.

In this study, we prospectively followed advanced and early breast cancer patients commencing chemotherapy to establish early alterations in markers of haemostasis and procoagulants. This study was undertaken to investigate the effect of cancer burden on chemotherapy-induced changes in biomarkers of haemostasis and to assess the utility of chemotherapy-induced changes in biomarker concentration in predicting VTE.

\section{MATERIALS AND METHODS}

\section{Patients}

A total of 123 female patients (median age 52 (range $31-78$ ) years) commencing chemotherapy for breast cancer were recruited. Of these, 87 were receiving adjuvant chemotherapy following curative surgery, and 36 were receiving chemotherapy for radiographically proven metastatic breast disease (Table 1). Patients were excluded if they were on anticoagulants, had a past history of VTE or had implanted vascular access devices.

\section{Control subjects}

Sixty-eight age-matched female controls (median age 48 (range $31-78$ ) years) with no history of cancer acted as control subjects.

\section{Protocol}

A prospective cohort study was undertaken. Markers of haemostasis (TAT, fibrinogen, D-dimer, platelet count), functional clotting assays (prothrombin time (PT) and activated partial thromboplastin time (APTT)) and procoagulants (TF, cancer procoagulant $(\mathrm{CP})$ and plasma vascular endothelial growth factor (pVEGF)) were measured before chemotherapy and at $24 \mathrm{~h}, 4$ days, 8 days and 3 months following commencement of chemotherapy in all patients. A clinical assessment for VTE was performed at the same time points. Bilateral screening full-leg duplex ultrasound imaging was performed by accredited vascular scientists (Society of Vascular Technologists) in all patients 1 month following commencement of chemotherapy, and repeated if symptoms developed.

Table I Chemotherapy regimens used in breast cancer patients

\begin{tabular}{lc}
\hline Chemotherapy regimen & Number of patients \\
\hline Adjuvant regimens & 65 \\
5-Fluorouracil, epirubicin, cyclophosphamide & 15 \\
Cyclophosphamide, methotrexate, 5-fluorouracil & 4 \\
Epirubicin, cyclophosphamide & 3 \\
Epirubicin & \\
& \\
Metastatic regimens & 15 \\
Docetaxol & 8 \\
Cyclophosphamide, methotrexate, 5-fluorouracil & 6 \\
Epirubicin, docetaxol & 3 \\
Vinorelbine, mitomycin & 2 \\
Epirubicin & 1 \\
5-Fluorouracil, epirubicin, cyclophosphamide & 1 \\
Vinorelbine, 5-fluorouracil & \\
\hline
\end{tabular}

\section{Blood sampling and analytical methods}

Atraumatic venous blood sampling was performed at the antecubital fossa, and all specimens were separated and stored within $2 \mathrm{~h}$ after being collected into tubes containing citrate and ETDA as anticoagulants. Citrate and EDTA samples were immediately taken onto ice, and serum samples were allowed to clot at room temperature. All samples (except full blood count and clotting screen) were centrifuged for $20 \mathrm{~min}$ at $4{ }^{\circ} \mathrm{C}$ and $2500 \mathrm{~g}$, and the plasma or serum was removed from the cells. Serum and citrated plasma samples were then divided into $0.3 \mathrm{ml}$ aliquots.

Platelet-depleted plasma (PDP) was also prepared for the analysis of VEGF as detailed: one of the citrated tubes was immediately plunged into ice and taken to the laboratory where the sample was centrifuged at $4{ }^{\circ} \mathrm{C}$ for $20 \mathrm{~min}$ at $3500 \mathrm{~g}$. The supernatant was removed and recentrifuged for $20 \mathrm{~min}$ at $3500 \mathrm{~g}$ at $4{ }^{\circ} \mathrm{C}$ following which the PDP was aliquoted and the last $0.5 \mathrm{ml}$ discarded. All samples were stored at $-80{ }^{\circ} \mathrm{C}$ until analysis.

Prothrombin time (normal range 9-13.5 s), APTT (normal range 16.5-24.5 s) and fibrinogen (normal range $1.5-5.0 \mathrm{gl}^{-1}$ ) were assayed by standard laboratory methods on ACL 3000 (Instrumentation Laboratory, Warrington, UK). Platelet count was measured using the Advia 120 Haematology System (Bayer Diagnostic, Newbury, UK). Serum TAT concentration was determined by a microplate immunoenzymatic method (Enzygnost ${ }^{\mathbb{R}}$ TAT micro ELISA, Dade Behring, Marburg, Germany), with a sensitivity of $1 \mu \mathrm{g} \mathrm{ml}^{-1}$. Plasma D-dimer samples were analysed by a quantitative fully automated ELISA assay using the VIDAS ${ }^{\mathbb{R}}$ D-Dimer (bioMérieux, Marcy l'Etoile, France) system, with a sensitivity of $45 \mathrm{ng} \mathrm{ml}^{-1}$ and upper limit of normal of $500 \mathrm{ng} \mathrm{ml}^{-1}$. Plasma TF was analysed using an enzyme-linked immunosorbent assay (ELISA) (American Diagnostica Inc., Greenwich, CT, USA), with a sensitivity of $10 \mu \mathrm{g} \mathrm{ml}^{-1}$. Cancer procoagulant was measured indirectly using a three-stage chromogenic assay to assess CP activity as described by Mielicki and co-workers (Mielicki et al, 1999). Platelet-depleted plasma VEGF was analysed using an ELISA by R\&D Systems ${ }^{\mathbb{R}}$ (Oxon, UK), with a sensitivity of $9 \mu \mathrm{g} \mathrm{ml}^{-1}$.

\section{Ethical approval}

The study was approved by the South Manchester Local Research Ethics Committee and all patients gave written informed consent.

\section{Statistical methods}

Data on PT, APTT platelet count and fibrinogen was parametric and thus reported as mean (confidence interval). Data on D-dimer, TAT, TF, CP and pVEGF was parametric after log conversion and so reported as geometric mean (confidence interval). Comparative group analysis (early, advanced breast cancer and controls) of prechemotherapy patient values was performed by ANOVA, with further analysis of subgroups using Scheffe. Comparative group analysis (VTE within 3 months, VTE free) of patient values was performed by independent $T$-test. Changes in patient serum or plasma values with chemotherapy as compared with pretreatment values were performed by paired T-test; however, to minimise errors induced by multiple tests, a repeated-measures analysis (Greenhouse Geiser correction) to compare trends over time in patients with and without VTE was used. Comparative group analysis (VTE within 3 months, VTE free) of changes in coagulation parameters with chemotherapy as compared with pretreatment values were performed by analysis of covariance. A significance of $P<0.05$ was used. Binary logistic regression to identify predictors of VTE was also performed. Analysis was performed on baseline data, and change from baseline. Appropriate corrections were made for cancer stage and age. 


\section{RESULTS}

Of 123 breast cancer patients receiving chemotherapy, $12(9.8 \%)$ patients developed VTE within 3 months of chemotherapy, of which $8(66.7 \%)$ were symptomatic. Six of $36(17 \%)$ metastatic breast cancer patients and 6 of $87(6.9 \%)$ early breast cancer patients receiving adjuvant chemotherapy developed VTE. Development of VTE was not related to age, menopausal status or tumour receptor expression.

\section{Baseline data: before chemotherapy}

Before chemotherapy, both APTT and PT were prolonged in advanced and early breast cancer patients, compared with controls $(P=0.01$ and 0.06 respectively, Table 2$)$. D-dimer, fibrinogen, TF, platelet count and pVEGF were all increased in advanced breast cancer compared with controls. TAT showed a similar trend. D-dimer, fibrinogen and pVEGF were increased in advanced breast cancer compared with early breast cancer, with TAT showing a similar trend. D-dimer and fibrinogen were increased in early breast cancer compared with controls (Table 2).

\section{Baseline data: development of VTE before chemotherapy}

Before chemotherapy, fibrinogen, D-dimer, TF and pVEGF were increased in patients who subsequently developed VTE within 3 months (fibrinogen: $4.9(3.0-6.9) \mathrm{gl}^{-1}, 3.4(3.2-3.7) \mathrm{gl}^{-1}$, $P=0.002 / 0.1, \quad$ D-dimer: $1655(834-3273) \mathrm{ng} \mathrm{ml}^{-1}, 727(631-$ 836) $\mathrm{ng} \mathrm{ml}^{-1}, P=0.003$; TF: $274 \quad(115-654) \mu \mathrm{g} \mathrm{ml}^{-1}, 107 \quad(86-$ 134) $\mu \mathrm{g} \mathrm{ml}^{-1}, \quad P=0.03$; pVEGF: $27.8(14.3-54.1) \mu \mathrm{g} \mathrm{ml}^{-1}, 15.4$ $(13.5-17.7) \mu \mathrm{g} \mathrm{ml}^{-1}, P=0.01$, VTE within 3 months and VTE free, respectively) (independent $T$-test). Similar trends were found when advanced breast cancer patients were analysed separately (fibrinogen: $4.1(3.3-4.9) \mathrm{gl}^{-1}, 6.9(3.7-10.1) \mathrm{gl}^{-1}, P=0.01$; D-dimer: $2769(1578-4859) \mathrm{ng} \mathrm{ml}^{-1}, 1148(806-1634) \mathrm{ng} \mathrm{ml}^{-1}, P=0.03$; TF: $271(117-627) \mu \mathrm{g} \mathrm{ml}^{-1}, 164(125-215) \mu \mathrm{g} \mathrm{ml}^{-1}, P=0.13$; pVEGF: $19.5(15.8-24.1) \mu \mathrm{g} \mathrm{ml}^{-1}, 49.6(15.3-160.7) \mu \mathrm{g} \mathrm{ml}^{-1}, \quad P=0.004$, VTE within 3 months and VTE free, respectively).

In both early and advanced breast cancer patients, prechemotherapy fibrinogen and D-dimer are predictors for the development of VTE. A 1-g increase in fibrinogen doubles the risk of VTE $(P=0.005)$, and every $1000 \mathrm{ng} \mathrm{ml}^{-1}$ increase in $\mathrm{D}$-dimer is associated with a 1.8 -fold increased risk of VTE $(P=0.005)$.
Utilising the clinical cutoff for D-dimer of $500 \mathrm{ng} \mathrm{ml}^{-1}$, thrombosis could be predicted with a sensitivity of $92 \%$, although specificity was low at $31 \%$. However, most importantly, the negative predictive value was $97 \%$. This has significant clinical relevance because nearly $30 \%$ of these breast cancer patients commencing chemotherapy had a D-dimer less than 500, and can therefore be almost guaranteed to be safe from VTE.

\section{Biomarker response to chemotherapy}

The mean or geometric mean (CI) of coagulation parameters at baseline, $24 \mathrm{~h}, 4$ days, 8 days and 3 months following chemotherapy is given in Table 3, and for patients subdivided into those developing VTE and remaining free of VTE, the values are given in Tables 4 and 5, respectively.

Analysing all patients together, irrespective of subsequent development of VTE, all molecules analysed showed a significant trend over time (repeated-measures analysis), except D-dimer and TF (repeated-measures analysis) (Table 3 ).

In patients with and without VTE, by 4 days following chemotherapy, platelet count was reduced; however, it remained within normal limits. Levels returned to baseline by 3 months (Table 3).

Activated partial thromboplastin time showed a marked shortening within $24 \mathrm{~h}$ of commencing chemotherapy; however, this was more pronounced in patients subsequently developing VTE $(P=0.002)$. Although the shortening in APTT was maintained up to 3 months, the difference between those with and without VTE was not apparent after $24 \mathrm{~h}$ (Tables 4 and 5).

Conversely, PT demonstrated a prolongation in response to chemotherapy, which at days 4 and 8 was more marked in patients developing VTE ( $P=0.06$ and 0.04 , respectively) (Tables 4 and 5).

When patients who subsequently developed VTE were compared with patients who remained free of VTE, there was no difference in the response to chemotherapy of fibrinogen, $\mathrm{D}$-dimer, $\mathrm{CP}$ and pVEGF (Tables 4 and 5).

Thrombin-antithrombin, in patients subsequently developing VTE, demonstrated a significant increase within $24 \mathrm{~h}$ in response to chemotherapy, which returned to baseline within 4 days $(P=0.02)$ (Tables 4 and 5). Interestingly, at this time point, 4 patients had TAT values greater than 10-fold the upper confidence interval. Three out of these four patients subsequently developed VTE.

Table 2 Baseline biomarker results before chemotherapy

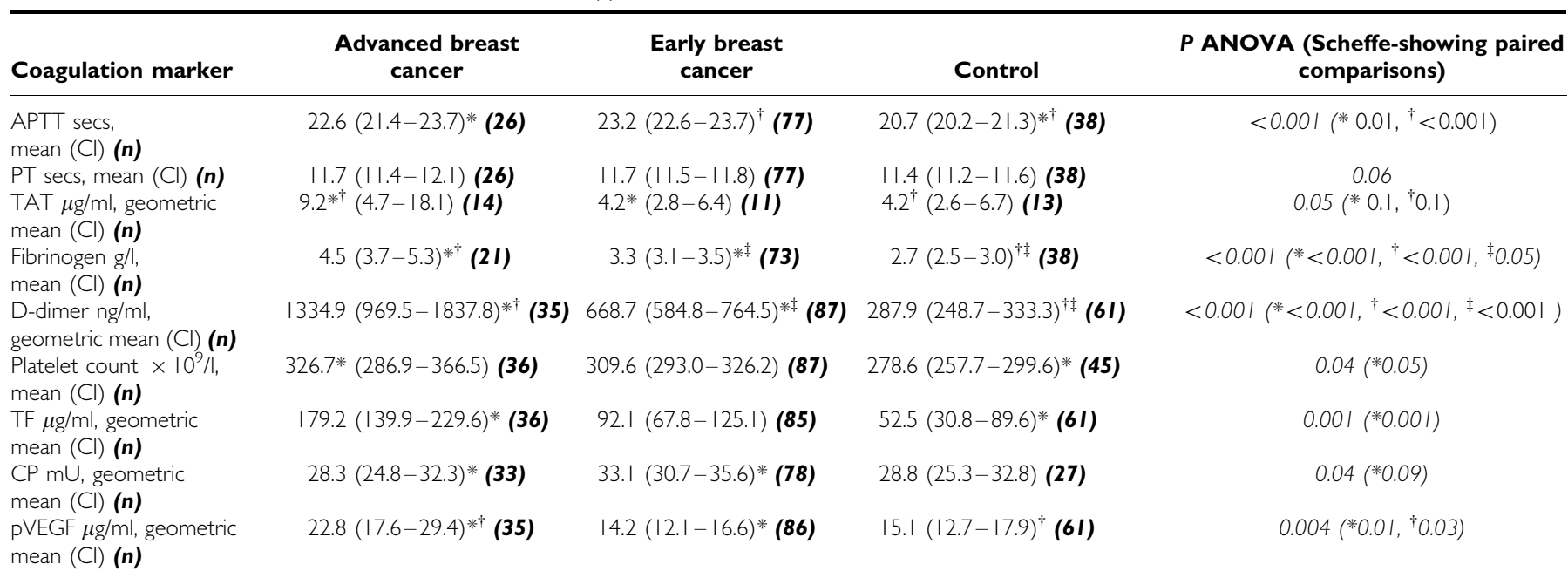

Analysis of the difference between groups used analysis of variance (ANOVA). Where differences were found, further analysis (between pairs of groups, with respective pairs for each molecule marked with $*^{\dagger},{ }^{\ddagger}$ and ${ }^{\S}$ ) was performed using Scheffe (95\% confidence interval $(\mathrm{Cl})$ ). 
Table 3 Alterations in biomarker parameters induced by chemotherapy in breast cancer patients

\begin{tabular}{|c|c|c|c|c|c|c|}
\hline $\begin{array}{l}\text { Procoagulant/ } \\
\text { adhesion molecule }\end{array}$ & $\begin{array}{l}\text { Prechemo- } \\
\text { therapy (n) }\end{array}$ & $\begin{array}{l}\text { Day I (post- } \\
\text { chemotherapy) (n) }\end{array}$ & $\begin{array}{c}\text { Day } 4 \text { (post- } \\
\text { chemotherapy) (n) }\end{array}$ & $\begin{array}{c}\text { Day } 8 \text { (post- } \\
\text { chemotherapy) (n) }\end{array}$ & $\begin{array}{l}3 \text { months (post- } \\
\text { chemotherapy) (n) }\end{array}$ & $\begin{array}{c}\text { Trend } \\
\text { over time } \\
\text { (repeated } \\
\text { measures, } \\
\text { GG) }\end{array}$ \\
\hline APTT s, mean $(\mathrm{Cl})$ & $23.0(22.5-23.5)(\mathbf{1 0 3})$ & $21.6(21.1-22.0)(\mathbf{1 0 8})$ & $21.4(21.0-21.8)(\mathbf{1 0 7})$ & $21.8(21.3-22.3)(\mathbf{1 0 8})$ & $21.0(20.5-21.5)(\mathbf{1 0 0})$ & $P<0.001$ \\
\hline PT s, mean $(\mathrm{Cl})$ & $11.7(11.5-11.8)(103)$ & $11.9(11.7-12.0)(108)$ & $11.7(11.6-\mid 1.9)(107)$ & $11.9(11.7-12.0)(108)$ & $11.5(11.3-\mid 1.7)(\mathbf{9 8})$ & $P<0.001$ \\
\hline $\begin{array}{l}\text { TAT } \mu \mathrm{g} \mathrm{ml}^{-1} \text {, } \\
\text { geometric mean }(\mathrm{Cl})\end{array}$ & $6.6(4.3-10.0)(\mathbf{2 5})$ & $11.3(5.9-21.4)(\mathbf{2 4})$ & $6.6(4.5-9.6)(\mathbf{2 4})$ & $5.6(4.0-7.8)(\mathbf{2 4})$ & $4.9(3.1-7.7)(\mathbf{2 0})$ & $P=0.04$ \\
\hline $\begin{array}{l}\text { Fibrinogen } \mathrm{gl}^{-1} \text {, } \\
\text { mean }(\mathrm{Cl})\end{array}$ & $3.6(3.3-3.8)(\mathbf{9 4})$ & $3.3(3.0-3.5)(\mathbf{9 8})$ & $3.2(2.9-3.4)(\mathbf{9 9})$ & $3.4(3.2-3.7)(104)$ & $4.1(3.8-4.3)(91)$ & $P<0.001$ \\
\hline $\begin{array}{l}\text { D-dimer ng ml }{ }^{-1} \text {, } \\
\text { geometric mean }(\mathrm{Cl})\end{array}$ & $815.3(707.8-939.3)$ (I 22) & 845.1 (729.3-979.1) (II5) & 786.7 (673.7-9|8.7) (II5) & $788.8(680.5-9 \mid 4.3)(\mathbf{I} / 6)$ & $763.3(650.9-895.2)(109)$ & $P=0.4$ \\
\hline $\begin{array}{l}\text { Platelet count } \\
\times\left. 10^{9}\right|^{-1} \text { mean }(\mathrm{Cl})\end{array}$ & $314.6(298.4-330.9)$ (I 23) & 306.1 (287.2-325.0) (99) & $263.3(249.7-276.8)(108)$ & $242.3(227.3-257.2)(\mathbf{I} \mathbf{I})$ & $310.0(285.0-334.0)(\mathbf{I} / \mathbf{2})$ & $P<0.001$ \\
\hline $\begin{array}{l}\mathrm{TF} \mu \mathrm{g} \mathrm{ml}^{-1} \text {, } \\
\text { geometric mean }(\mathrm{Cl})\end{array}$ & II $2.3(89.0-14 \mid .6)($ (I2I) & I 6.3 (9|.2- |48.2) (I I6) & $97.8(76.9-124.3)(I / 3)$ & $97.3(77.3-122.4)$ (II 5) & $94.1(74.0-119.8)($ (107) & $P=0.3$ \\
\hline $\begin{array}{l}\mathrm{CP} \mathrm{mU} \text {, } \\
\text { geometric mean }(\mathrm{Cl})\end{array}$ & $31.6(29.6-33.7)(I I I)$ & $36.4(34.1-38.8)(109)$ & $34.4(32.2-36.7)(\mathbf{1 0 4})$ & $32.0(29.8-34.3)(\mathbf{1 0 8})$ & $30.9(28.8-33.1)(100)$ & $P<0.001$ \\
\hline $\begin{array}{l}\text { PVEGF } \mu \mathrm{g} \mathrm{ml}^{-1} \text {, } \\
\text { geometric mean }(\mathrm{Cl})\end{array}$ & $16.4(14.2-18.8)(\mathbf{I 2 0})$ & $14.9(13.2-16.9)(115)$ & $16.3(14.0-18.0)(I / 2)$ & $20.5(18.3-13.0)(1 / 4)$ & $21.6(18.8-24.9)(106)$ & $P<0.001$ \\
\hline
\end{tabular}

Table 4 Alterations in biomarker parameters induced by chemotherapy in breast cancer patients developing VTE within 3 months of chemotherapy

\begin{tabular}{|c|c|c|c|c|c|}
\hline Coagulation marker & Prechemotherapy (n) & $\begin{array}{c}\text { Day I (post- } \\
\text { chemotherapy) (n) }\end{array}$ & $\begin{array}{c}\text { Day } 4 \text { (post- } \\
\text { chemotherapy) (n) }\end{array}$ & $\begin{array}{c}\text { Day } 8 \text { (post- } \\
\text { chemotherapy) (n) }\end{array}$ & $\begin{array}{l}3 \text { months (post- } \\
\text { chemotherapy) (n) }\end{array}$ \\
\hline APTT secs, mean (Cl) & $22.2(18.7-25.6)(9)$ & $19.8(18.2-21.3)(9)$ & $21.1(19.4-22.7)(I I)$ & $21.6(19.4-23.7)(\mathbf{8})$ & $21.0(18.6-23.4)(9)$ \\
\hline PT secs, mean $(\mathrm{Cl})$ & | $1.5(|| .0-12.0)(9)$ & $11.9(\mid 1.5-12.4)(I I)$ & II.9(II.4-12.4)(II) & $12.1(11.3-12.9)(9)$ & II.8 (10.9-12.6) (7) \\
\hline $\begin{array}{l}\text { TAT } \mu \mathrm{g} \mathrm{ml}^{-1} \text {, geometric } \\
\text { mean }(\mathrm{Cl})\end{array}$ & $8.9(2.4-32.5)(\mathbf{8})$ & $28.6(4.9-167.1)(8)$ & $6.3(2.4-16.4)(8)$ & $5.2(2.4-\mid 1.1)(\mathbf{8})$ & $3.9(2.5-5.9)(\mathbf{7})$ \\
\hline Fibrinogen $\mathrm{gl}^{-1}$ mean $(\mathrm{Cl})$ & $4.9(3.0-6.9)(\mathbf{7})$ & $4.2(2.5-5.9)(\mathbf{8})$ & $4.2(2.9-5.5)(\mathbf{1 0})$ & $4.4(3.0-5.7)(\mathbf{7})$ & $5.6(4.5-6.8)(\mathbf{8})$ \\
\hline $\begin{array}{l}\text { D-dimer ng ml } \\
\text { geometric mean }(\mathrm{Cl})\end{array}$ & $1618.6(979.0-2676.1)(12)$ & I653.I (996.0-2743.8) (II) & 1297.| (585.2-2875.1) (II) & $1301.9(642.4-2638.6)(I I)$ & $966.7(504.9-1850.8)(9)$ \\
\hline $\begin{array}{l}\text { Platelet count } \\
\times\left. 10^{9}\right|^{-1} \text { mean }(\mathrm{Cl})\end{array}$ & $342.5(265.8-419.2)(\mathbf{I})$ & $338.9(246.4-431.4)(\mathbf{1 0})$ & $269.6(225.5-313.8)(I I)$ & $274.0(216.8-331.2)(I I)$ & $386.2(238.3-534.1)(\mathbf{1 0})$ \\
\hline $\begin{array}{l}\text { TF } \mu \mathrm{g} \mathrm{m}^{-1} \text {, } \\
\text { geometric mean }(\mathrm{Cl})\end{array}$ & $231.1(104.1-513.2)(I I)$ & $228.7(107.1-488.5)(\mathbf{1 0})$ & $190.9(96.9-376.4)(10)$ & $192.9(82.2-452.5)(\mathbf{1 0})$ & $81.4(22.9-289.5)(\mathbf{8})$ \\
\hline $\mathrm{CP} \mathrm{mU}$, geometric mean $(\mathrm{Cl})$ & $31.4(26.6-37.1)(I I)$ & 35.7 (28.4-44.9) (III) & $32.5(26.3-40.1)(I I)$ & $28.2(22.9-34.7)(I I)$ & $27.8(21.2-36.5)(\mathbf{9})$ \\
\hline $\begin{array}{l}\text { pVEGF } \mu \mathrm{g} \mathrm{ml}^{-1} \\
\text { geometric mean }(\mathrm{Cl})\end{array}$ & $27.8(14.3-54.1)(\mathbf{I})$ & $19.5(10.4-36.6)(I I)$ & $19.0(9.4-38.3)($ (II) & $23.4(|3.2-4| .5)(I I)$ & $18.7(13.7-25.5)(9)$ \\
\hline
\end{tabular}

Tissue factor showed marked alterations in response to chemotherapy in those with and without VTE at 3 months. Tissue factor demonstrates a more marked decrease at 3 months, compared with baseline in patients subsequently developing VTE $(P=0.02)$, even when corrections are made for cancer stage (Tables 4 and 5). Of these early alterations in coagulation in response to chemotherapy, only the prolongation of PT is an independent predictor for chemotherapy-induced thrombosis. The absence of an increase of PT at 8 days, relative to baseline, has a negative predictive power of $100 \%$. As this occurs in $45 \%$ of patients, these individuals could be identified as no-risk for thrombosis on the basis of the change in PT at day 8 .

\section{DISCUSSION}

This study supports previously published data on the frequency of VTE in breast cancer chemotherapy, with a rate of $17 \%$ in advanced breast cancer (Goodnough et al, 1984) and 8\% (Weiss et al, 1981; Levine et al, 1988; von Tempelhoff et al, 1996) in early breast cancer patients receiving adjuvant therapy.

The increase in APTT and PT in breast cancer patients before chemotherapy suggests a paradoxical prolongation of clotting times, compared with non-cancer controls. Previous smaller studies have not demonstrated such a prolongation, but in all studies, the control groups were not matched to the study group. (Canobbio et al, 1986; Parmar et al, 1990; Mielicki et al, 1999; Oberhoff et al, 2000).
An increase in markers of the clotting system in advanced cancer, compared with early breast cancer, and early breast cancer compared with controls is demonstrated in this study by D-dimer and fibrinogen, confirming previous studies (Falanga et al, 1998; Blackwell et al, 2000; Oberhoff et al, 2000; Dirix et al, 2002). However, unlike previous research, in our study, the early breast cancer group has undergone complete tumour excision, but in spite of this, D-dimer levels remain elevated, perhaps implying a prolonged postoperative thrombotic response.

Elevated circulating TF levels in breast cancer have been described previously (Lwaleed et al, 1999; Ueno et al, 2000). Thrombocytosis has been described previously in cancer patients. (Sun et al, 1979; Pedersen and Milman, 1996).

The elevated prechemotherapy TAT levels in advanced breast cancer patients in this study support previous findings in breast (Falanga et al, 1998; Donati and Falanga, 2001), lung (Gabazza et al, 1992; Seitz et al, 1997) and colorectal cancer (Iversen et al, 1996; Iversen and Thorlacius-Ussing, 2002).

Consistent with previously published literature, pVEGF levels in this study are significantly elevated in advanced breast cancer patients (Adams et al, 2000). Interestingly, levels in the early breast cancer group (following apparent complete surgical resection) are comparable with controls. Previous literature report increased levels in early breast cancer patients before surgery, implying a resolution of elevated levels (Heer et al, 2001).

In this study, we have found, before chemotherapy, significantly elevated levels of D-dimer and fibrinogen in patients who subsequently develop VTE. Both markers are predictive for increased 
Table 5 Alterations in biomarkers induced by chemotherapy in breast cancer patients remaining free of VTE within 3 months of chemotherapy

\begin{tabular}{|c|c|c|c|c|c|}
\hline Coagulation marker & Prechemotherapy (n) & $\begin{array}{l}\text { Day I (post- } \\
\text { chemotherapy) (n) }\end{array}$ & $\begin{array}{c}\text { Day } 4 \text { (post- } \\
\text { chemotherapy) (n) }\end{array}$ & $\begin{array}{c}\text { Day } 8 \text { (post- } \\
\text { chemotherapy) (n) }\end{array}$ & $\begin{array}{l}3 \text { months (post- } \\
\text { chemotherapy) (n) }\end{array}$ \\
\hline APTT s, mean (Cl) & $23.1(22.6-23.6)(\mathbf{9 4})$ & $21.8(21.3-22.2)(\mathbf{9 7})$ & $21.5(21.1-21.9)(\mathbf{9 6})$ & $21.8(21.3-22.3)(\mathbf{9 9})$ & $21.0(20.5-21.5)(91)$ \\
\hline $\mathrm{PT} s$, mean $(\mathrm{Cl})$ & $11.7(11.6-11.9)(\mathbf{9 4})$ & $11.9(11.7-12.0)(97)$ & $11.7(11.6-11.9)(\mathbf{9 6})$ & $11.8(11.7-12.0)(99)$ & $11.5(11.3-11.7)(91)$ \\
\hline $\begin{array}{l}\text { TAT } \mu \mathrm{g} \mathrm{ml}^{-1} \text {, geometric } \\
\text { mean }(\mathrm{Cl})\end{array}$ & $5.7(4.0-8.0)($ I 7$)$ & $7.1(4.4-11.3)(16)$ & $6.7(4.5-10.2)(16)$ & $5.8(3.8-8.6)(\mathbf{1 6})$ & $5.6(2.8-11.2)(\mathbf{1 3})$ \\
\hline Fibrinogen $\mathrm{gl}^{-1}$, mean $(\mathrm{Cl})$ & $3.4(3.2-3.7)(\mathbf{8 7})$ & $3.2(2.9-3.4)(\mathbf{9 0})$ & $3.1(2.8-3.3)(\mathbf{8 9})$ & $3.4(3.1-3.6)(\mathbf{9 7})$ & $3.9(3.6-4.2)(\mathbf{8 3})$ \\
\hline $\begin{array}{l}\text { D-dimer ng ml } \\
\text { geometric mean }(\mathrm{Cl})\end{array}$ & $756.6(655.9-872.7)(\mathbf{I} \mathbf{1 0})$ & $787.1(677.5-914.5)(104)$ & $746.3(640.7-869.1)(104)$ & $748.4(646.1-867.0)(105)$ & $747.2(632.5-882.7)(\mathbf{1 0 0})$ \\
\hline $\begin{array}{l}\text { Platelet count } \\
\times 10^{9} \mathrm{I}^{-1} \text { mean }(\mathrm{Cl})\end{array}$ & $311.6(295.2-328.0)(I I I)$ & $302.4(283.4-321.4)(\mathbf{8 9})$ & $262.5(248.1-277.0)(\mathbf{9 7})$ & $239.0(223.4-254.5)(\mathbf{1 0 6})$ & $302.5(279.6-325.5)(\mathbf{I 0 2})$ \\
\hline $\begin{array}{l}\mathrm{TF} \mu \mathrm{g} \mathrm{ml}^{-1} \\
\text { mean }(\mathrm{Cl})\end{array}$ & $104.4(82.0-133.1)(\mathbf{1} 10)$ & 109.| (84.5- 140.9) (106) & $91.7(7|.1-1| 8.2)$ (103) & $91.2(71.8-115.7)$ (105) & $95.3(74.3-122.1)$ (99) \\
\hline 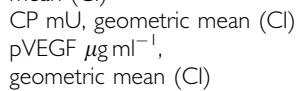 & $\begin{array}{l}31.6(29.4-33.9)(\mathbf{1 0 0}) \\
15.4(13.5-17.7)(\mathbf{1 0 8})\end{array}$ & $\begin{array}{l}36.5(34.1-39.1)(\mathbf{9 8}) \\
14.5(12.9-16.4)(\mathbf{1 0 4})\end{array}$ & $\begin{array}{l}34.6(32.3-37.1)(\mathbf{9 3}) \\
16.0(13.7-18.7)(\mathbf{I 0 I})\end{array}$ & $\begin{array}{l}32.4(30.1-34.9)(\mathbf{9 7}) \\
20.2(18.0-22.7)(\mathbf{1 0 3})\end{array}$ & $\begin{array}{l}31.2(29.0-33.6)(\mathbf{9 1}) \\
21.9(18.8-25.5)(\mathbf{9 7})\end{array}$ \\
\hline
\end{tabular}

risk of VTE. Preoperative plasma levels of soluble fibrin polymers have been found to correlate with development of VTE following elective neurosurgery (Sonaglia et al, 1999).

A population-based prospective study has demonstrated a strong, positive relationship between D-dimer and development of future VTE (Cushman et al, 2003). Elevated presurgery D-dimer, before development of VTE, has been reported previously in patients undergoing hip surgery (Bongard et al, 1994; CoFrancesco et al, 1997). However D-dimer did not predict for VTE in medical or surgical patients admitted to ICU (Crowther et al, 2005), or in two studies of 71 and 60 ovarian cancer patients undergoing surgery (Olt et al, 1990; von Tempelhoff et al, 1997). In 50 early breast cancer patients undergoing chemotherapy, von Tempelhoff et al (1996) reports an elevated mean prechemotherapy D-dimer in the five patients subsequently developing VTE. In a small study investigating the anti-angiogenic compound SU5415 (an inhibitor of VEGF receptor 1 and 2), pretreatment TF levels were significantly elevated in the three patients who subsequently developed VTE, compared with the 17 patients without VTE (Kuenen et al, 2002), supporting our findings.

To date, no study has found a clinically useful test for predicting VTE; however, in this study, we demonstrate that a subgroup of patients (approximately one-third) can be considered as with minimal risk of VTE (D-dimer $<500 \mathrm{ng} \mathrm{ml}^{-1}$ prechemotherapy), so that thromboprophylaxis can be targeted to a more precise high-risk group.

The almost universal, significant response of the measured molecules to breast cancer chemotherapy demonstrates that chemotherapy has a significant effect on coagulation and supports previous studies (Canobbio et al, 1986; Rogers et al, 1988; Feffer et al, 1989; Rella et al, 1996; Pectasides et al, 1999).

A shortening of APTT, in response to chemotherapy, has previously been reported; however, here we provide evidence that this response occurs within $24 \mathrm{~h}$ of commencing treatment and may be influential in VTE development. Both Pectasides and Canobbio (Canobbio et al, 1986; Pectasides et al, 1999) show shortening of functional clotting assay times equivalent to our 3-month findings. In lung cancer patients receiving chemotherapy, Gabazza et al (1992) reports an early shortening of APTT (at days 2, 5 and 7 following treatment) and a slightly later shortening of PT (at days 5, 7 and 14 following treatment). The fact worthy of note in the current study is that the shortening of APTT is more pronounced in the group subsequently developing VTE. Interestingly, Lowe et al (1999) report that a shortened preoperative APTT is the only independent predictor for post-hip surgery DVT in a study of 480 patients. The marked prolongation of PT at 8 days, occurring only in patients who subsequently develop VTE, has not been reported previously. Our current study is the first to identify such early alterations in functional clotting studies in response to breast cancer chemotherapy and, more importantly, that these alterations are more marked in patients subsequently developing VTE.
The finding that a lack of prolongation of PT from prechemotherapy to day 8 identifies a subgroup at no risk of VTE has profound clinical importance. A simple clotting study before commencement of treatment and at the 1-week outpatient appointment may half the number of patients that require thromboprophylaxis.

It is surprising that products of intravascular coagulation, such as fibrinogen and D-dimer show no significant alteration in response to chemotherapy in the prothrombotic VTE group.

The early changes we have demonstrated in clotting, particularly those changes occurring within $24 \mathrm{~h}$ (TAT and APTT), are too rapid to be caused by immobility secondary to chemotherapyinduced malaise, or biochemical and fluid alterations with emesis. The peak onset of VTE following total hip replacement is 4 days (Sikorski et al, 1981). The true time of onset for chemotherapyinduced VTE would require more extensive screening than was performed in this study; however, early haemostatic responses to chemotherapy may further upregulate a haemostatic system that is already induced, due to cancer and recent surgery. A small study of 16 advanced cancer patients treated with chemotherapy demonstrated an increase in plasma fibrinopeptide A (cleaved from fibrinogen by thrombin) within $45 \mathrm{~min}$ of chemotherapy administration; however, this response was abolished in 8 patients given a second course of chemotherapy when treatment was preceeded by heparin infusion (Edwards et al, 1990).

In conclusion, our large prospective study was the first study to look at early alterations in haemostasis following breast cancer chemotherapy, and the first to screen for VTE and relate such alterations to development of VTE. We have confirmed that chemotherapy-induced alterations occur early, within $24 \mathrm{~h}$, of chemotherapy. Early alterations in functional clotting assays are more marked in patients subsequently developing VTE. Early use of thromboprophylaxis, perhaps even a single dose administered before chemotherapy, may abolish this rapid haemostatic response. We also present a method of identifying a subgroup of patients at minimal risk of VTE, thus allowing targeted thromboprophylaxis. A trial of single-dose thromboprophylaxis in this subset may be warranted.

\section{ACKNOWLEDGEMENTS}

We acknowledge the financial assistance of Cancer Research UK during the course of this study. CCK was in receipt of a Royal College of Surgeons of England research fellowship.

\section{Conflict of interest}

None declared. 


\section{REFERENCES}

Adams J, Carder PJ, Downey S, Forbes MA, MacLennan K, Allgar V, Kaufman S, Hallam S, Bicknell R, Walker JJ, Cairnduff F, Selby PJ, Perren TJ, Lansdown M, Banks RE (2000) Vascular endothelial growth factor (VEGF) in breast cancer: comparison of plasma, serum, and tissue VEGF and microvessel density and effects of tamoxifen. Cancer Res 60: $2898-2905$

Blackwell K, Haroon Z, Broadwater G, Berry D, Harris L, Iglehart JD, Dewhirst M, Greenberg C (2000) Plasma D-dimer levels in operable breast cancer patients correlate with clinical stage and axillary lymph node status. J Clin Oncol 18: 600-608

Bongard O, Wicky J, Peter R, Simonovska S, Vogel JJ, de Moerloose P, Reber G, Bonameaux H (1994) D-dimer plasma measurement in patients undergoing major hip surgery: use in the prediction and diagnosis of postoperative proximal vein thrombosis. Thromb Res 74: 487-493

Canobbio L, Fassio T, Ardizzon A, Bruzzi P, Queirolo MA, Zarcone D, Di Giorgio F, Rosso R, Santi L (1986) Hypercoagulable state induced by cytostatic drugs in stage II breast cancer patients. Cancer 58: $1032-1036$

Clahsen PC, van de Velde CJ, Julien JP, Floiras JL, Mignolet FY (1994) Thromboembolic complications after perioperative chemotherapy in women with early breast cancer: a European Organization for Research and Treatment of Cancer Breast Cancer Cooperative Group study. J Clin Oncol 12: $1266-1271$

Cofrancesco E, Cortellaro M, Corradi A, Ravasi F, Bertocchi F (1997) Coagulation activation markers in the prediction of venous thrombosis after elective hip surgery. Thromb Haemost 77: 267 - 269

Crowther MA, Cook DJ, Griffith LE, Meade M, Hanna S, Rabbat C, Bates SM, Geerts W, Johnston M, Guyatt G (2005) Neither baseline tests of molecular hypercoagulability nor D-dimer levels predict deep venous thrombosis in critically ill medical-surgical patients. Intensive Care Med 31: $48-55$

Cushman M, Folsom AR, Wang L, Aleksic N, Rosamond WD, Tracey RP (2003) Fibrin fragment D-dimer and the risk of future venous thrombosis. Blood 101: $1243-1248$

Dirix LY, Salgado R, Weytjens R, Colpaert C, Benoy I, Huget P, Van Dam P, Prove A, Lemmens J, Vermeulen P (2002) Plasma fibrin D-dimer levels correlate with tumour volume, progression rate and survival in patients with metastatic breast cancer. Br J Cancer 86: 389-395

Donati MB, Falanga A (2001) Pathogenetic mechanisms of thrombosis in malignancy. Acta Haematol 106: $18-24$

Dvorak HF, Van DeWater L, Bitzer AM, Dvorak AM, Anderson D, Harvey VS, Bach R, Davis GL, DeWolf W, Carvalho AC (1983) Procoagulant activity associated with plasma membrane vesicles shed by cultured tumor cells. Cancer Res 43: 4434-4442

Edwards RL, Klaus M, Matthews E, McCullen C, Bona RD, Rickless FR (1990) Heparin abolishes the chemotherapy-induced increase in plasma fibrinopeptide A levels. Am J Med 89: 25-28

Falanga A, Lwvine MN, Consonni E, Gritti G, Delaini F, Oldani E, Julian JA, Barbui T (1998) The effect of very-low-dose warfarin on markers of hypercoagulation in metastatic breast cancer: results from a randomized trial. Thromb Haemost 79: 23-27

Feffer SE, Carmosino LS, Fox RL (1989) Acquired protein C deficiency in patients with breast cancer receiving cyclophosphamide, methotrexate, and 5-fluorouracil. Cancer 63: $1303-1307$

Gabazza EC, Taguchi O, Yamakami T, Machishi M, Ibata H, Tsutsui K, Suzuki S (1992) Coagulation-fibrinolysis system and markers of collagen metabolism in lung cancer. Cancer 70: 2631-2636

Ginsberg JS, Brill-Edwards P, Panju A, Patal A, McGinnis J, Smith F, Dale I, Johnston M, Ofosu F (1995) Pre-operative plasma levels of thrombin-antithrombin III complexes correlate with the development of venous thrombosis after major hip or knee surgery. Thromb Haemost 74: $602-605$

Goodnough LT, Saito H, Manni A, Jones PK, Pearson OH (1984) Increased incidence of thromboembolism in stage IV breast cancer patients treated with a five-drug chemotherapy regimen. A study of 159 patients. Cancer 54: $1264-1268$

Heer K, Kumar H, Read JR, Fox JN, Monson JR, Kerin MJ (2001) Serum vascular endothelial growth factor in breast cancer: its relation with cancer type and estrogen receptor status. Clin Cancer Res 7: $3491-3494$

Iversen LH, Okholm M, Thorlacius-Ussing O (1996) Pre- and postoperative state of coagulation and fibrinolysis in plasma of patients with benign and malignant colorectal disease - a preliminary study. Thromb Haemost 76: $523-528$
Iversen LH, Thorlacius-Ussing O (2002) Relationship of coagulation test abnormalities to tumour burden and postoperative DVT in resected colorectal cancer. Thromb Haemost 87: $402-408$

Kirwan CC, Nath E, Byrne GJ, McCollum CN (2003) Prophylaxis for venous thromboembolism during treatment for cancer: questionnaire survey. Br Med J 327: 597 - 598

Kuenen BC, Levi M, Meijers JC, Kakkar AK, van Hinsbergh VW, Kostense PJ, Pinedo HM, Hoekman K (2002) Analysis of coagulation cascade and endothelial cell activation during inhibition of vascular endothelial growth factor/vascular endothelial growth factor receptor pathway in cancer patients. Arterioscler Thromb Vasc Biol 22: $1500-1505$

Levine MN, Gent M, Hirsh J, Armold A, Goodyear MD, Hryniuk W, DePauw S (1988) The thrombogenic effect of anticancer drug therapy in women with stage II breast cancer. $N$ Engl J Med 318: $404-407$

Lowe GD, Haverkate F, Thompson SG, Turner RM, Bertina RM, Turpie AG, Mannucci PM (1999) Prediction of deep vein thrombosis after elective hip replacement surgery by preoperative clinical and haemostatic variables: the ECAT DVT Study. European Concerted Action on Thrombosis. Thromb Haemost 81: 879-886

Lwaleed BA, Chisholm M, Francis JL (1999) Urinary tissue factor levels in patients with breast and colorectal cancer. J Pathol 187: $291-294$

Mielicki WP, Tenderenda M, Rutkowski P, Chojnowski K (1999) Activation of blood coagulation and the activity of cancer procoagulant (EC 3.4.22.26) in breast cancer patients. Cancer Lett 146: $61-66$

Miller B, Heilmann L (1988) Hemorheologic variables in breast cancer patients at the time of diagnosis and during treatment. Cancer 62: $350-354$

Oberhoff C, Rollwagen C, Tauchert AM, Hoffman O, Winkler UH, Schindler AE (2000) Perioperative development of a thrombogenic risk profile in patients with carcinomas of the breast: a cause of increased thrombosis. Eur J Gynaecol Oncol 21: $560-568$

Olt GJ, Greenberg C, Synan I, Coleman RE, Clarke-Pearson D (1990) Preoperative assessment of fragment D-dimer as a predictor of postoperative venous thrombosis. Am J Obstet Gynecol 162: $772-775$

Ozyilkan O, Baltali E, Ozdemir O, Tekuzman G, Kirazli S, Firat D (1998) Haemostatic changes; plasma levels of alpha2-antiplasmin-plasmin complex and thrombin-antithrombin III complex in female breast cancer. Tumori 84: $364-367$

Parmar J, Taylor I, Roath S, Francis J (1990) Procoagulant activity in whole blood from patients with breast and colorectal cancer. Blood Coagul Fibrinolysis 1: $127-132$

Pectasides D, Tsaudaridis D, Aggouridaki C, Tsavdaridou V, Visvikis A, Tsatalas K, Fountzilas G (1999) Effects on blood coagulation of adjuvant CNF (cyclophosphamide, novantrone, 5-fluorouracil) chemotherapy in stage II breast cancer patients. Anticancer Res 19: $3521-3526$

Pedersen LM, Milman N (1996) Prognostic significance of thrombocytosis in patients with primary lung cancer. Eur Respir J 9: 1826-1830

Rella C, Coviello M, Giotta F, Maiello E, Colavito P, Colangelo D, Quaranta M, Colucci G, Schittulli F (1996) A prothrombotic state in breast cancer patients treated with adjuvant chemotherapy. Breast Cancer Res Treat 40: $151-159$

Rogers JS, Murgo AJ, Fontana JA, Raich PC (1988) Chemotherapy for breast cancer decreases plasma protein C and protein S. J Clin Oncol 6: $276-281$

Seitz R, Heidtmann HH, Wolf M, Immel A, Egbring R (1997) Prognostic impact of an activation of coagulation in lung cancer. Ann Oncol 8: $781-784$

Seward J, Byrne GJ, Howell A, Bundred NJ, McCollum CN (1999) Does cytotoxic chemotherapy precipitate venous thromboembolism in patients with cancer. Breast Cancer Res Treat 57: 57

Sikorski JM, Hampson WG, Staddon GE (1981) The natural history and aetiology of deep vein thrombosis after total hip replacement. J Bone Joint Surg Br 63: $171-177$

Sonaglia F, Agnelli G, Baroni M, Severi P, Quintaualla R, D’Angelo SV (1999) Pre-operative plasma levels of soluble fibrin polymers correlate with the development of deep vein thrombosis after elective neurosurgery. Blood Coagul Fibrinolysis 10: 459-463

Sun NC, McAfee WM, Hum GJ, Weiner JM (1979) Hemostatic abnormalities in malignancy, a prospective study of one hundred eight patients. Part I. Coagulation studies. Am J Clin Pathol 71: 10-16 
Ueno T, Toi M, Koike M, Nakamura S, Tominaga T (2000) Tissue factor expression in breast cancer tissues: its correlation with prognosis and plasma concentration. $\mathrm{Br} J$ Cancer 83: $164-170$

von Tempelhoff GF, Dietrich M, Hommel G, Heilmann L (1996) Blood coagulation during adjuvant epirubicin/cyclophosphamide chemotherapy in patients with primary operable breast cancer. J Clin Oncol 14: 2560-2568 von Tempelhoff GF, Dietrich M, Neimann F, Schneider D, Hommel G, Heilmann L (1997) Blood coagulation and thrombosis in patients with ovarian malignancy. Thromb Haemost 77: 456-461

Weiss RB, Tormey DC, Holland JF, Weinberg VE (1981) Venous thrombosis during multimodal treatment of primary breast carcinoma. Cancer Treat Rep 65: 677-679 